\title{
Surgimiento y muerte del capitalismo extractivo
}

\author{
James Petras* \\ Henry Veltmeyer** \\ Traducción del inglés de Luis Rodolfo Morán Quiroz.
}

La reprimarización de la economía supone el cambio de la industrialización por sustitución de importaciones a una dependencia de la exportación agro-mineral.

Los regímenes de centro-izquierda emanados de los movimientos populares que derrocaron a regímenes neoliberales son impulsores de la reprimarización bajo la bandera del antineoliberalismo y el antiimperialismo. Estos regímenes

firman convenios con las corporaciones multinacionales, pilares de esta estrategia de crecimiento.

Proposiciones generales

A REPRIMARIZACIÓN de la economía (RepE) implica un cambio de la diversificada industrialización por sustitución de importaciones a una dependencia creciente de la exportación agro-mineral.

La RepE es especialmente pronunciada y adoptada por los regímenes de centro-izquierda ( $\mathrm{RCI}$ ) deriva-

*Profesor emérito de Sociología en la Universidad de Binghamton, Nueva York, Estados Unidos.

***:Docente-investigador de la Unidad Académica de Estudios del Desarrollo de la Universidad Autónoma de Zacatecas, México. dos de los movimientos populares que derrocaron a regímenes neoliberales.

La RepE es promovida bajo las banderas del antineoliberalismo e incluso del antiimperialismo, aun mientras los RCI firman contratos a largo plazo y gran escala con una amplia variedad de corporaciones multinacionales (CMN) que se han convertido en importantes actores en la estrategia de crecimiento.

La política de RepE constituye una adaptación pragmática a varias circunstancias internas y externas: la incapacidad o dificultad de los sectores privado y estatal para desarrollar una economía nacional industrial de alta tecnología y oportunidades, altos precios y explotación relativamente lucrativa de los mer- 
cados internacionales en Asia por medio de "sociedades" con las CNM.

$\mathrm{Al}$ apoyarse en el capitalismo extractivo, los regímenes de centro-izquierda se convierten en complejos Estados rentistas que recolectan regalías, "rentas", provenientes de las materias primas de exportación.

Los ciclos de las mercancías del pasado son reemplazados por mega-ciclos, a medida que los precios favorables de las mercancías durante décadas reemplazan las fluctuaciones de un año al otro. El flujo estable de ingresos deriva en presupuestos estables y financia las importaciones sin súbitos y abruptos déficits presupuestarios y comerciales (y problemas de la balanza de pagos).

La acumulación de reservas extranjeras, la disciplina presupuestal, una estrecha contabilidad fiscal - esencialmente las políticas fiscales ortodoxas del Estado - aseguran el flujo de entrada de capital y la apreciación de la divisa local. La apreciación de la moneda acentúa aún más la RepE a medida que los productos industriales pierden competitividad en precios debido a los altos costos de producción.

La RepE se convierte, paradójicamente, en parte de un sindrome de estabilización (ss) en la economía política mundial. El crecimiento estable a largo plazo, una divisa estable, finanzas estables, cuentas externas estables, presupuestos estables, una estabilidad social y política relativa y la reelección o continuidad de los funcionarios en la rama ejecutiva (presidentes), son rasgos esenciales de la ss.

En contraste con la Unión Europea y Estados Unidos, la RepE latinoamericana no enfrenta una crisis fiscal, financiera y de balanza de pagos... ni tampoco enfrenta el nivel de inquietud social que se encuentra en el sur de Europa.

El resultado divergente entre Unión Europea/Estados Unidos y América Latina se deriva de las diferencias en los regímenes desregulatorios: los primeros desregularon el sector financiero en perjuicio de los sectores productivos al crear economías hiperfinancieras sujetas a severas manipulaciones del mercado por especuladores. En el segundo contexto se desreguló el sector extractivo en respuesta a una creciente demanda proveniente de Asia por sus productos, derivando en inversiones a gran escala, largo plazo, crecimiento estable y rentas lucrativas.

La yuxtaposición de una ideología antiimperialista y la RepE ha llevado a una doble polarización: por un lado, entre los regímenes de centro-izquierda y el establecimiento en Washington y, por el otro, entre las coaliciones extractoras público-privadas y las comunidades eco-autóctonas.

Durante la mayor parte de la pasada década, los regímenes extractores de centro-izquierda (Reci) que dependían de las exportaciones primarias han obtenido la mayor parte del conflicto con sus adversarios tanto externos como internos.

Debido a la diversidad de sus mercados, los consistentemente altos precios de sus exportaciones y los contratos renegociados con las cun que aumentaron los ingresos del Estado, los Reci han resistido con éxito la presión económica de Estados Unidos y han evitado acudir al Fondo Monetario Internacional (FMI). Dado que cuentan con balanzas comerciales excedentes y amplias reservas en divisas extranjeras, no han requerido préstamos para la balanza de pagos y han formado alianzas regionales latinoamericanas - como la Alianza Bolivariana para los Pueblos de Nuestra América (Alba) - que les ofrecen cierto grado de seguridad respecto a la intervención de Estados Unidos.

Debido a sus ingresos sustanciosos y a un crecimiento razonablemente alto y estable, los Reci han sido capaces de financiar programas de pobreza, hacer concesiones salariales, ampliar los gastos sociales y cooptar liderazgos de sindicatos y movimientos sociales. A partir de su retórica antiimperialista, llamados populistas y organización electoral clientelista, los Reci han rebatido, repetida y decisivamente, los desafíos provenientes de la derecha tradicional que se inclina a favor de Estados Unidos y han aislado y marginado a los desafíos electorales provenientes de los movimientos sociales eco-autóctonos y de la izquierda radical.

Perfil y desempeño de los Reci

El Reci ha presidido más de una década de crecimiento sostenido en el producto interno bruto (PIB) que va de 3 a $8 \%$. El crecimiento en el sector extractivo en términos de inversión, comercio, ingresos y producción a veces ha excedido los dobles dígitos. Nuevas inversiones a largo plazo y gran escala están en proceso de realización y hay pocos signos de que el megaciclo esté por terminar.

No todo es de fácil navegación: las protestas campesinas indígenas han derivado en cierto bloqueo e incluso cancelación de contratos mineros, y las huelgas mineras han derivado en alguna limitación temporal de la producción. El pronóstico para el futuro in- 
mediato es que haya continuidad de la década anterior de crecimiento, cambios incrementales, y una continuada dependencia en el sector extractivo como la fuerza motriz del crecimiento.

El perfil político y económico, empero, muestra algunas vulnerabilidades profundas en el mediano plazo, en especial debido al descenso en la diversidad económica y la alta dependencia en los mercados de materias primas. Además, la mayor parte de los Reci están basados en líderes en el poder altamente personalistas, cuyo gobierno es limitado y cuyo carisma les da el "cemento" que une entre sí a los elementos contradictorios - CvN y clases populares.

Vulnerabilidades de los Reci

A pesar de los éxitos macroeconómicos y electorales de los Reci, la estrategia de desarrollo está sujeta a varias vulnerabilidades que resultan perjudiciales para la gran mayoría de la población trabajadora y amenazan la sustentabilidad del modelo.

Procederemos enumerando los principales indicadores de desempeño de forma telegráfica, acompañados de un breve comentario.

\section{INDICADORES ECONÓMICOS}

Los productos primarios constituyen un creciente porcentaje de las ganancias por las exportaciones de América Latina, en especial entre los Reci. Esto es causa y consecuencia del descenso en la actividad del sector industrial y es resultado de una estrategia deliberada del régimen. Históricamente, la dependencia respecto a las materias primas ha derivado en una gran volatilidad en la economía, una estructura de clase altamente polarizada y en un gobierno oligárquico.

La concentración en la exportación de productos primarios ha estado acompañada de una creciente concentración de la propiedad, en especial por el capital extranjero en el sector extractivo, con frecuencia asociado con los tecnócratas del sector público con estrechas ligas pasadas y probablemente futuras con el sector privado. Un conjunto paralelo de lucrativas consultarías satélite surge junto con casas de inversión dedicadas a realizar contratos, fusiones y adquisiciones para aumentar el alcance de las operaciones de las empresas conjuntas. La concentración de la propiedad está íntimamente correlacionada con el crecimiento de megamillonarios y la concentración de la riqueza. Las firmas capitalistas y bancarias privadas de origen nacional se unen a las sociedades y se benefician de dar servicio a las firmas extractivas del Estado y de las CMN. Las CMN, los tecnócratas, casas de inversión, consultarías y banqueros se convierten en la nueva clase gobernante en los Reci.

Los pagos por regalías e impuestos están lejos de ser los óptimos aún cuando algunos de los contratos de pagos mínimos realizados en el pasado han sido renegociados para aumentar los pagos al país "anfitrión”. Los "incentivos invisibles", las cláusulas de depreciación, los pagos por transferencias, las facturas infladas de los costos de operación, salarios exorbitantes, permiten a las Cun reducir los pagos de regalías y de impuestos sobre las ganancias aun cuando nominalmente las tasas hayan aumentado, privando de ingresos a la hacienda local.

La ganancia constituye el meollo de un juego que hace que las materias primas sean una empresa tan rentable. Las cun que se dedican a las industrias extractivas han obtenido ganancias agregadas sin precedente a lo largo de la década en múltiples puntos de la cadena productiva: primero, en la venta de materias primas, luego en la comercialización y el procesamiento, así como en la venta inicial de los insumos (maquinaria, químicos, etcétera). La porción del precio final de una materia prima ya procesada que va a las Cun excede con mucho el ingreso para el "país fuente".

Cuando mucho, las ganancias son sólo parcialmente reinvertidas en el lugar de la explotación de los bienes primarios. La mayor parte de ellas se exporta a la oficina matriz y se convierte en salarios de los ejecutivos, bonos, dividendos o es reinvertida en diversos sectores, en lugares de ultramar con un mínimo efecto multiplicador en el país anfitrión. Una fracción mínima de las ganancias se invierte en mejorar las habilidades y la tecnología locales y en diversificar la economía del país que exporta las mercancías por agregar valor a la materia prima.

Es mínimo el porcentaje de materias primas que es procesado localmente en bienes terminados y con alto contenido de valor. La mayor parte de las Cun y sus socios en los Estados toman el "camino fácil” burocrático-rentista de la explotación de las materias primas y, cuando mucho, la refinación y fundición, añadiendo escaso valor. Como consecuencia, los empleos de gran valor se generan en el mercado de origen de las CMN mientras que el lugar dinámico de la explotación de 
materias primas se conserva como un enclave privilegiado en medio de la pobreza y el subdesarrollo económico. La especialización en materias primas deriva en un patrón de desarrollo extremadamente desigual entre el enclave y el resto de la economía y la sociedad. Esto, a su vez, genera una estructura de clase geográfica y socialmente polarizada en la cual los bloques regionalmente ubicados de multiclases compiten y entran en conflicto por la riqueza y los ingresos acaparados por el Estado. El papel del Estado como "mediador" o redistribudor entre el enclave rico en recursos y el resto de la economía social está comprometido por sus lazos y contratos con las cun y la "carrera" y los "intereses de clase" de los tecnócratas con una biografía de vínculos con el capital internacional.

Aunque la exportación de materias primas, en especial en una época de altos precios, genera una balanza de pagos generalmente favorable, no obstante el hecho de que la mayor parte del capital y los bienes intermedios y los servicios profesionales y la tecnología son comprados de manufactureros, banqueros y consultorías extranjeras, deriva en el deslizamiento de las ganancias hacia ultramar y en la reproducción del atraso tecnológico nacional. Las Reci han producido fertilizantes, químicos, maquinaria agrícola, sistemas de semillas e irrigación; el entrenamiento de los agrónomos y especialistas locales para ofrecer conocimientos técnicos y estableecr programas de extensión crearía una economía competitiva de clase mundial capaz de reducir su dependencia del financiamiento extranjero y de las decisiones externas capaces de alterar los puntos de inversión y producción.

INDICADORES SOCIALES Y CAPITALISMO EXTRACTIVO

Aunque la mayor parte de los regímenes de capital extractivo declaran "sembrar las ganancias" en programas sociales, cuando mucho, casi todos esos regímenes tan sólo se comprometen en los incrementos graduales en el gasto social dirigidos a los "espacios de pobreza extrema" y a la supervivencia de subsistencia. Con excepción de Venezuela, pocos programas sociales incluyentes a gran escala y a largo plazo están diseñados y son financiados para ofrecer empleo bien remunerado, salud y educación públicas universales y gratuitas, pensiones generales que permitan vivir bien y alimentos a bajo costo y subsidios a la vivienda. En vez de ello, el gasto social se dirige a crear programas clientelistas contra la pobreza que sirven a extrechos intereses electorales en vez de generar una ciudadanía sana, educada, productiva y participativa. La imagen de un campesino pobre sentado en una montaña de metales preciosos conserva relevancia en la mayoría de las economías capitalistas extractivas.

La práctica común de los regímenes extractivos es concentrar el ingreso, las ganancias, los gastos y altos salarios en las ciudades capitales. En contraste, las economías locales y las regiones de explotación extractiva reciben una proporción infinitamente menor de las inversiones del Estado en infraestructuras sociales y económicas.

Las carreteras y el transporte se construyen para vincular los sitios de explotación con sus destinos en ultramar, en la forma de una "maza de rueda". La alternativa, un patrón "cuadriculado" vincularía la explotación con el mercado interno, las ciudades, los pueblos y villas del interior, y con las fábricas que producen insumos nacionales y procesan materias primas.

Aunque los funcionarios del Estado y de las CMN citan los salarios relativamente altos que van a los trabajadores con sueldos y salarios en el sector de la extracción en comparación con los trabajadores fuera del enclave, la comparación más relevante la constituyen las razones entre trabajo/ganancia dentro del enclave, las razones de ganancias frente a productividad y el valor generado y la razón de salarios, bonos y pagos por dividendos a la élite, comparadas con el promedio de ingresos por sueldo/salario de los trabajadores fuera de la gerencia. Las disparidades entre los salarios ejecutivos/ gerenciales y los correspondientes a los trabajadores en la minería, agricultura y energía se han dado en espiral a medida que los precios y ganancias realizadas han aumentado durante la década pasada.

La mayor parte de los grandes proyectos mineros, agrícolas y de energía son intensivos en capital: altamente mecanizados, con grandes insumos de tecnología avanzada y con el empleo de un pequeño cuadro de ingenieros, empleados y administradores (divididos entre extranjeros y nacionales) y un pequeño porcentaje de fuerza de trabajo. Cada millón de dólares invertido genera un empleo. La relación capital-trabajo, en especial tras de que se ha terminado la construcción inicial de la infraestructura, más intensiva en mano de obra, impacta poco al desempleo. La fuerza de trabajo que participa en la economía local más intensiva en mano de obra que ha sido alterada por las inversiones en extracción resulta marginada. Aunque en términos agrega- 
dos el capital invertido en la economía extractiva sobrepasa con mucho el capital invertido en la economía local, los costos para los productores locales, tanto en términos de la pérdida de formas de sustento, ingreso y salud y deterioro en la salud es sustancial y probablemente derive en un resultado neto negativo. En otras palabras, desde un análisis de costo-beneficio, las cur y el Estado pueden obtener ganancias sustantvas mientras los productores locales sufren una pérdida neta en términos materiales y personales: ruptura de los lazos comunitarios y de las relaciones recíprocas, y la alteración de la familia y el parentesco.

Las mujeres son notoriamente las más grandes perdedoras "invisibles" como consecuencia de las alteraciones en la economía local causadas por el capital extractivo a gran escala. Las mujeres juegan un papel integral en la agricultura familiar, las artesanías locales, los textiles, la cerámica, el tejido de alfombras y la produción de lácteos, así como en la comercialización e intercambio vinculados con la producción en pequeña escala de mercancías. Cuando el capital extractivo a través de contratos entre cun-Estado desplaza o debilita la economía local (por medio de la contaminación), contrata casi exclusivamente trabajadores varones, confinando a las mujeres a un papel marginal, obligando a las mujeres jóvenes a migrar, buscar trabajo en los servicios personales o en ocupaciones semi-lícitas-ilícitas (prostitución, meseras). Además, los "efectos colaterales" son extremadamente demandantes del tiempo y la energía de las mujeres en el tratamiento de los padecimientos y enfermedades difundidos por los productos y usos químicos. Una amplia gama de contaminantes tiene un importante impacto en los niños, las mujeres embarazadas, las personas de edad avanzadas los varones empleados con ocupaciones extractivas directa e indirectamente de alto riesgo - la "enfermería" familiar es abrumadoramente una obligación no pagada de las mujeres - . Una apropiación del capital extractivo significa, para las mujeres, una pérdida de ingresos, estatus, vida social (comercialización) y una mayor subordinación dentro de la familia.

Las inversiones en minería y energía llevan capital a una región pero también añaden costos sociales. Por cada dólar invertido, la economía regional se ve agobiada por el costo de tratar con el flujo de llegada de criminales, prostitutas, alcoholismo, drogadicción, apuestas, enfermedades venéreas, crímenes y otros costos más allá de lo presupuestado de carácter anti-social. Mientras que las ganancias son privatizadas, los costos del rompimiento social agobian a la comunidad, el gobierno local y la economía.

La industria extractiva se caracteriza por una estructura de clase de múltiples niveles, altamente desigual y polarizada. En la parte más alta están las multinacionales y sus socios nacionales - el $\mathrm{I} \%$ de los multimillonarios (y billonarios) que ganan un múltiplo de todo el resto de la fuerza laboral -. El siguiente nivel de gerencia superior, constituye una mezcla de directores extranjeros y locales, traídos desde fuera de la región y que interactúan con los circuitos internacionales. Debajo de ellos están las gerencias de ingeniería y mandos intermedios que operan el proceso de producción cotidiana y supervisan las relaciones laborales - esta última parte puede también incluir a un "local" que tiene ciertos antecedentes como antiguo abogado laboral o sindicalista - . Siguen en la jerarquía los empleados de oficina, que incluyen empleados regionales y a trabajadores transferidos desde las ciudades. Dependiendo del grado de mecanización, estos varían en número, hasta una tercera parte de la fuerza de trabajo, con una escala específica de pagos y prestaciones y con una organización social que los diferencia de los trabajadores manuales. El siguiente estrato es el de los trabajadores "estables" o "permanentes" (una categoría relativa) con contratos indefinidos y prestaciones que incluyen subsidios para vivienda y otros rubros. Forman hasta una mitad de la fuerza de trabajo manual. Debajo de ellos están los trabajadores temporales con la paga más baja, la mayor inseguridad en el empleo, con escasas o nulas prestaciones y que se dedican al trabajo más riesgoso e insalubre. Además, hay trabajadores temporales "migratorios" que son contratados para proyectos específicos como construcción de caminos y para la reparación y otros proyectos a corto plazo. Además existe un ejército de reserva de "migrantes" desempleados que ofrecen "servicios" de dudoso valor social y productivo y que podrían servir como esquiroles.

La segmentación laboral constituye una estrategia de los patrones para reducir el poder colectivo de la fuerza de trabajo y fortalecer el poder de negociación del capital. La fragmentación y la competencia enfrentan a los trabajadores entre sí. El capital extractivo disuelve la solidaridad y los esfuerzos de cooperación que incluyan a todos los miembros de una comunidad. Cuando mucho, la solidaridad y la unidad dependen de la capacidad de los trabajadores manuales sindicalizados de construir vínculos con las clases cercanas y con los productores y comerciantes en pequeña escala. 
El punto es que el capital extractivo genera pocos empleos estables y calificados con un ingreso decente y una gran cantidad de empleos auxiliares sin prestaciones definidas y escasas perspectivas de futuro, en especial para aquellos empleados en ocupaciones de alto riesgo y con tendencia a las enfermedades.

La expectativa de vida está limitada en muchas ocupaciones extractivas. Esto significa que las ganancias de toda una vida de los trabajadores pueden acabar siendo menos de los correspondientes a trabajadores que se dedican a actividades familiares más saludables. Lo mismo puede decirse para la seguridad familiar: aunque los trabajadores empleados en el sector de la extracción adquieren modernos aparatos electrónicos y para el hogar, las enfermedades ocupacionales pueden derivar en un despido temprano, inopia y menores ingresos a lo largo de la vida (en el largo plazo).

\section{INDICADORES AMBIENTALES}

El capitalismo extractivo es probablemente el mayor contaminador del mundo y los trabajadores de las minas y las comunidades adyacentes a ellas son los más afectados. Los testimonios y los estudios de parte de los ecologistas que trabajan con comunidades indígenas en Ecuador, Perú y Bolivia han documentado amplias enfermedades debido a los derrames de petróleo, acuíferos contaminados, ríos y tierras agrícolas anexas y entre los residentes, en especial los niños pequeños. Aunque la industria extractiva ha incrementado los recursos del Estado, los costos en términos de recursos naturales destruidos debido a la contaminación, desarrollo de infrastructura y daños colaterales a la vida comunitaria, tienen un gran peso en la balanza. Tal es especialmente el caso si consultamos las tasas de mortalidad y la decadencia en la calidad de vida de los trabajadores y residentes afectados por enfermedades inducidas por el capital extractivo. El alcance y la profundidad de la contaminación y los costos económicos en la mayoría de los casos empobrecen a las comunidades locales superando con mucho cualquier ganancia monetaria derivada de los sueldos y salarios que se entregan a una fuerza de trabajo reducida.

El tenaz esfuerzo de los capitalistas extractivos por explotar las materias primas los hace pasar por encima de la actividad económica preexistente. La agricultura local, el cultivo de los alimentos básicos y la crianza de ganado, son devastadas y los productores locales son desplazados, el agua para la irrigación es desviada hacia las minas y plantaciones, y las carreteras y mercado están saturados de transporte pesado. Los químicos tóxicos debilitan la salud de los productores locales. El lanzamiento del capitalismo extractivo se aparea con la alteración de la producción local, con fuertes dislocaciones sociales e incrementos en la marginalidad social; a medida en que crecen las minas en alcance e ingresos, decae la economía doméstica.

Las afirmaciones de los defensores del capital extractivo en el sentido de que la fuerza de trabajo desplazada de la producción doméstica será reabsorbida en los nuevos empleos creados en el sector minero son la excepción y no la regla. La agricultura de mano de obra intensiva, la artesanía y la crianza de ganado emplea a muchos más trabajadores, de ambos géneros, que el sector minero intensivo en capital. Además, el complejo de accidente-enfermedad que acompaña a la minería genera un ciclo de trabajo más corto, convirtiendo a los trabajadores desechados en cargas para los hogares con ingresos y recursos cada vez menores. El resultado neto es que el capital extractivo se beneficia del marco temporal más productivo del ciclo de vida, y la comunidad y el hogar se ven cargados por el costo del sostenimiento de la fuerza de trabajo en su etapa menos productiva.

INDICADORES POLÍTICOS

Las decisiones respecto al ingreso, la ubicación, las condiciones de operación y el impacto ambiental del capital extractivo se realizan por medio de acuerdos entre los ejecutivos de una pequeña élite en la capital y los consejeros delegados de las multinacionales (CEOs) de las CMN.

Un análisis de las estructuras de toma de decisiones revela la exclusión de esas comunidades, los ciudadanos locales y los líderes más afectados. La iniciativa de invertir es influida por lo general por una combinación de incentivos y concesiones a la élite - a costa de la hacienda local - y concesiones de tierras en términos favorables para las cun. Se toman poco o nada en cuenta los impactos locales en las formas de vida, la salud y los sistemas productivos preexistentes. La estructura de la toma de decisiones está centrada en la élite, es urbana, y corporativa; los estudios de impacto ambiental se realizan por "consultarías" patrocinadas por la élite que invariablemente aprueban los proyectos lucrativos.

La participación de los ciudadanos es mínima en un principio, en especial en lo que se refiere al alcance, diseño y operaciones de los proyectos extractivos. Sin embargo, a medida que el proyecto progresa hacia un esta- 
tus operativo, los ciudadanos, las comunidades y amplios sectores de la sociedad civil son movilizados en varios niveles. La influencia negativa en la economía existente, el impacto dañino en el ambiente, la distribución desigual de los ingresos, los bajos niveles de empleo local, la pequeña contribución al bienestar de la comunidad y otros temas relacionados genera la ira de la comunidad local y con frecuencia deriva en protestas masivas.

El patrón típico es uno en el cual deciden las élites y las comunidades locales responden. Enfrentado por una dura oposición, el régimen responde con violencia - represión de Estado - conservando el poder, privilegios y prerrogativas de los capitalistas extractivos. En segundo lugar, enfrentado por una oposición amplia, el régimen y las CMN intentan negociar con los líderes locales o cooptarlos, haciendo limitadas concesiones respecto a proyectos sociales locales, pero nunca cediendo el acuerdo básico con la élite o el sistema de toma de decisiones. Se seleccionan "grupos de consulta” simbólicos pero sin que tengan poder de revisar o controlar el proceso de extracción.

En una escala autoritaria de participación ciudadana, la estructura de la toma de decisiones que acompaña el ingreso del capital extractivo y los términos de la explotación, es altamente centralizada y autoritaria. En contraste, la oposición local se ubica en un nivel alto en participación ciudadana asumiendo la forma de asambleas, debates, formulación de acción política y social y con respecto a las negociacioes de resolución.

Las elecciones y los debates desempeñan un escaso o nulo papel en el ingreso del capital extractivo. Los tecnócratas que no tienen puestos de elección, los banqueros, inversionistas, juegan el papel dominante fuera del ámbito público sin alguna consideración democrática. En contraste, la oposición de la comunidad es encabezada por líderes electos con un mandato (revocable) derivado de una asamblea general y que debe rendir ante una "reunión del pueblo".

La élite de quienes toman las decisiones está preocupada exclusivamente por las decisiones a corto plazo que se ocupan de los más bajos costos para la explotación, extracción y transportación de recursos primarios. Dejan que la comunidad local lidie con los desastres a largo plazo que por lo general se dan como secuela de la erosión: deslizamientos de tierra, rupturas en las presas de desechos, inundaciones subterráneas y otras adversidades "a largo plazo". En contraste, las comunidades locales están preocupadas por los efectos a largo plazo y las decisiones estratégicas que impactan la supervivencia y la prosperidad local en el largo plazo.
Hay un conflicto básico de interés encarnado en la relación entre el capital extractivo y sus patrocinadores centrales en el Estado frente a las comunidades locales, la sociedad civil y los movimientos indígenas.

Conclusión

El capital extractivo en su estructura realmente existente, en sus operaciones e impacto tuvo un efecto agudamente polarizante, según se mide por indicadores económicos, sociales, ambientales y políticos precisos.

La clave es la inequidad: la desigual distribución de los beneficios y los costos, la desigual distribución del poder político y los desiguales costos de la contaminación ambiental. La inequidad deriva de la concentración de poder económico en las estructuras jerárquicas internacionales del capital, reforzada y ampliada por el ejecutivo político local (el régimen) que impone, por decreto, los términos por los cuales el capital extractivo explota los recursos naturales. Las comunidades locales y la fuerza de trabajo enfrentan el mayor costo en términos de las consecuencias adversas de una economía fundamentada en los recurosos naturales, reciben la menor porción de las ganancias e ingresos y las mayores pérdidas en términos de salud, ciudadanía y cultura cívica. Las contrastantes fortunas entre el capital y el trabajo son más agudas en los "pueblos de las compañías" en donde un "control total" virtual de las CMN y del Estado obliga a las comunidades a participar en movilizaciones a gran escala para corregir las menores injusticias cotidianas.

Aunque el espacio de la explotación detona el conflicto, la resolución en gran parte depende de la capacidad de cada parte de movilizar el apoyo en una comunidad política nacional e internacional de mayor magnitud. Las CMN movilizan sus vínculos con los sectores "financieros-de exportación-de importación" y el Estado para convocar a las fuerzas armadas y la clase media alta; la comunidad local moviliza las capitales provinciales, pueblos y villas y los partidos urbanos de izquierda, sindicatos y ONGs ecologistas.

La resolución del conflicto depende de la fuerza de las fuerzas contendientes. El resultado tiene consecuencias vitales no sólo para aquellas comunidades directamente afectada sino en toda la estructura de la economía y la estructura de clase. El capital extractivo al mando tiende a polarizar a la sociedad en dos; genera una economía "mono-cultural" vulnerable a los ciclos (mega o no); reduce la participación ciudadana, acentúa los flujos de capital especulativo desde y hacia las mercancías. 


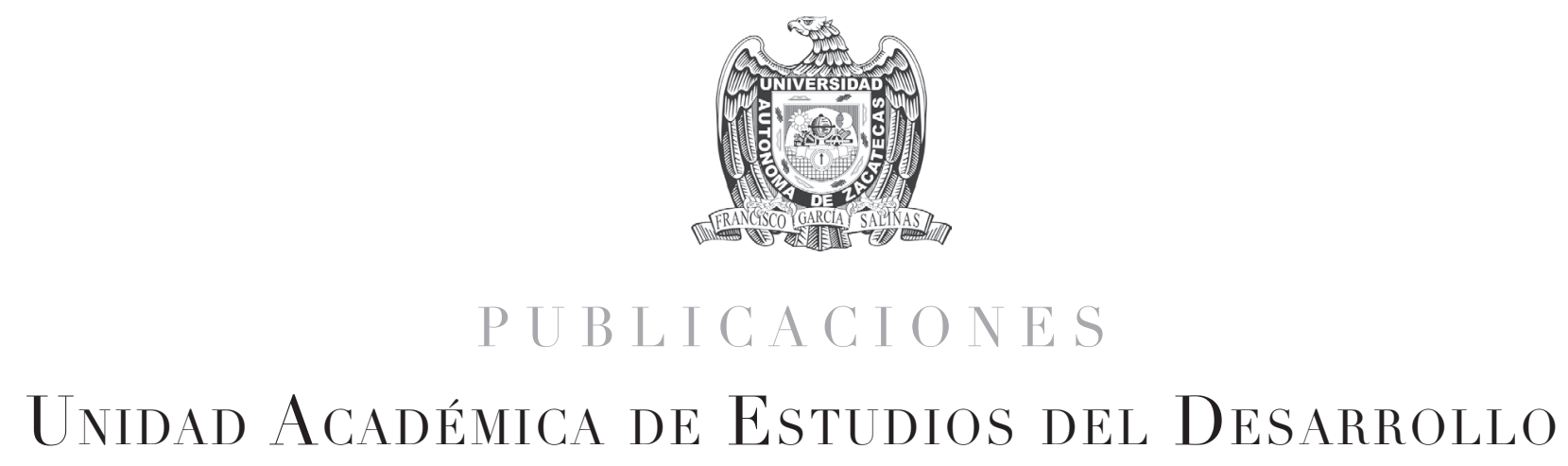

THE NEW EXTRACTIVISM

A Post-Neoliberal Development Model

or Imperialism of the Twenty-First Century?

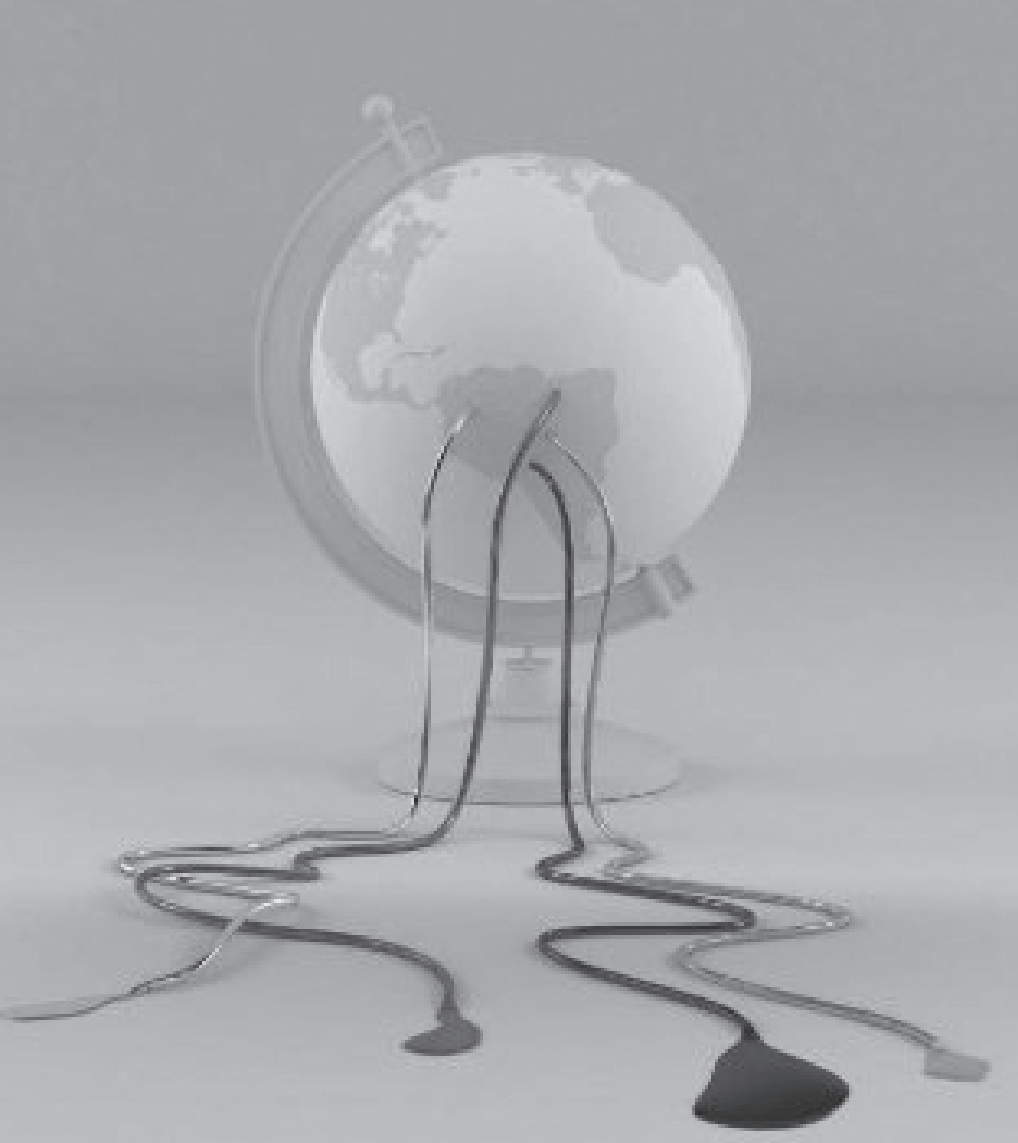

Henry Veltmeyer and James Petras (Z 